\title{
Formation and photoluminescence of zirconia dendrites in borosilicate glass-ceramics
}

\author{
Yasuhiro NOBUTA, Yoshihiro TAKAHASHI ${ }^{\dagger}$, Takamichi MIYAZAKI*, Nobuaki TERAKADO, \\ Noriko ONOUE**, Tsuyoshi SHINOZAKI** and Takumi FUJIWARA \\ Department of Applied Physics, Tohoku University, 6-6-05 Aoba, Aoba-ku, Sendai 980-8579, Japan \\ * Department of Instrumental Analysis, Tohoku University, 6-6-11 Aoba, Aoba-ku, Sendai 980-8579, Japan \\ ${ }^{* *}$ Department of Cardiovascular Medicine, National Hospital Organization, Sendai Medical Center, \\ 8-8, 2-chome, Miyagino, Miyagino-ku, Sendai 983-8520, Japan
}

\begin{abstract}
We prepared a borosilicate glass, in which the $\mathrm{ZrO}_{2}$ phase is singly crystallizable, i.e., $15 \mathrm{Na}_{2} \mathrm{O}-15 \mathrm{ZrO}_{2}-30 \mathrm{~B}_{2} \mathrm{O}_{3}-40 \mathrm{SiO}_{2}$ glass, and investigated the texture and morphology of the resulting glass-ceramics. $\mathrm{ZrO}_{2}$ dendrites with a tetragonal system (hightemperature phase) were developed as initial phase, and the tetragonal phase was transformed to the monoclinic phase (lowtemperature phase) by elongation of the heat-treatment time, and finally the needle-/rod-like crystals on a scale of few hundred nanometers were obtained. The glass-ceramics with monoclinic $\mathrm{ZrO}_{2}$ showed photoluminescence around $480 \mathrm{~nm}$ by excitation in the ultraviolet region. The effect of $\mathrm{TiO}_{2}$-addition on the photoluminescent property was also considered.
\end{abstract}

(02017 The Ceramic Society of Japan. All rights reserved.

Key-words : Glass-ceramics, Zirconia, Photoluminescence, Rare-earth free

[Received January 4, 2017; Accepted January 21, 2017]

\section{Introduction}

A promising way to create the nanostructured materials is glassceramic (GC) processing, i.e., structural ordering in glass evolved by thermal stimulation. Glass structures possess a disordered random-network, resulting in flexibility and formability, and a great deal of effort has gone into creation of functional materials based on GC processing so far: ${ }^{1)-4)}$ The GCs consisting of an emissive phase with rare-earth (RE)-dopant has also been fabricated for applications as photoluminescent (PL) materials, e.g., white-LED, long-lasting phosphor, and optical thermometer. ${ }^{5)-7)}$ PL phenomena have a great potential, not only for emissive-/ photovoltaic-device components, but also for bio-imaging applications $^{8), 9)}$ that contribute to our cultural, sustainable, and healthy lifes. For instance, in vivo observation of temperature in tissue using PL material has absorbed much attentions recently, ${ }^{10)}$ and is considered to be helpful for a medical treatment, in which temperature-monitoring is a key to improving the quality of the treatment. ${ }^{11)}$

Zirconia $\left(\mathrm{ZrO}_{2}\right)$ is a wide-bandgap dielectrics, and is also utilized to synthesize an engineering ceramics and artificial teeth because of its high chemical durability and harmless. In addition, blue PL phenomena have been studied in $\mathrm{ZrO}_{2}$ in 1960's: Sarver reported the broad PL band with peak at $\sim 480 \mathrm{~nm}$ by ultraviolet (UV) excitation in pure and Ti-doped $\mathrm{ZrO}_{2},{ }^{12)}$ and an afterglow PL by X-ray excitation was also reported by Bettinali et al. ${ }^{13)}$ Recently, it is of particular interest to elucidate the PL phenomena and to improve their performance because of the emissive phase free from any RE-dopants. At first, origin of the blue $\mathrm{PL}$ is considered to be the presence of Ti as an impurity. ${ }^{12)}$ On the

Corresponding author: Y. Takahashi; E-mail: takahashi@laser. apph.tohoku.ac.jp

* Corresponding author: T. Fujiwara; E-mail: fujiwara@laser.apph. tohoku.ac.jp other hand, Emeline et al. attribute an oxygen-vacancy to a luminescent center. ${ }^{14)}$ Although the origin of luminescence center is thus still controversial, ${ }^{15)-20)} \mathrm{ZrO}_{2}$ has attracted much attention because of being a great candidate for RE-free phosphor. In this study for the purpose of fabricating $\mathrm{ZrO}_{2}$-crystllized $\mathrm{GCs}$, we therefore studied the crystallization behavior of glass, in which $\mathrm{ZrO}_{2}$ is included as a main constituent, and observed the texture and morphology in obtained GC samples. The PL properties of the samples also examined.

\section{Experimental}

\subsection{Preparation of precursor glass and glass- ceramics}

Although there are many literatures concerning crystallization in glass with $\mathrm{ZrO}_{2}$ so far, the $\mathrm{ZrO}_{2}$ is added as a nuclear agent so that its amount is limited up to a few or less than $\sim 10 \mathrm{~mol} \%$. On the other hand, Maschio and Scardi reported single crystallization of a $\mathrm{ZrO}_{2}$ phase in $10 \mathrm{Na}_{2} \mathrm{O}-10 \mathrm{ZrO}_{2}-20 \mathrm{~B}_{2} \mathrm{O}_{3}-60 \mathrm{SiO}_{2}$ glass. ${ }^{21)} \mathrm{As}$ pre-examination for this study, we attempted to prepare glass with the same composition and checked the precipitated phase after crystallization. However, the glass crystallized the $\mathrm{ZrO}_{2}$ and cristobalite $\left(\mathrm{SiO}_{2}\right)$ phases. For single crystallization of the $\mathrm{ZrO}_{2}$ phase, we also checked several glass compositions, in which the $\mathrm{SiO}_{2}$ content was less than the previous glass. As a result, we successfully prepared $15 \mathrm{Na}_{2} \mathrm{O}-15 \mathrm{ZrO}_{2}-30 \mathrm{~B}_{2} \mathrm{O}_{3}-40 \mathrm{SiO}_{2}$ glass, in which only the $\mathrm{ZrO}_{2}$ phase is crystallizable. Therefore, this glass was employed as the base precursor thereafter. In addition, a base precursor substituting a small amount of $\mathrm{TiO}_{2}$ for $\mathrm{ZrO}_{2}$, i.e., $15 \mathrm{Na}_{2} \mathrm{O}-(15-x) \mathrm{ZrO}_{2}-x \mathrm{TiO}_{2}-30 \mathrm{~B}_{2} \mathrm{O}_{3}-40 \mathrm{SiO}_{2}$ glass $(x=0.01$, $0.03,0.05)$ was also prepared in order to examine the Ti-additive effect on the PL properties in the resulting GCs.

The precursor glasses were prepared by a conventional meltquenching method. The chemical reagents of $\mathrm{Na}_{2} \mathrm{CO}_{3}, \mathrm{ZrO}_{2}$, $\mathrm{TiO}_{2}, \mathrm{~B}_{2} \mathrm{O}_{3}$, and $\mathrm{SiO}_{2}$ powders were mixed with an alumina mortar, and the mixtures were melted in a platinum crucible with 
a lid at $1450^{\circ} \mathrm{C}$ for $1 \mathrm{~h}$ in air atmosphere. The as-quenched precursor showed a halo pattern in the X-ray diffraction (XRD) pattern, indicating that the precursor was in glassy state. The thermal parameters of the base precursor were determined by means of a differential thermal analysis at a heating rate of $10 \mathrm{~K} / \mathrm{min}$, and the glass-transition, crystallization-onset, and crystallization-peak temperatures were estimated to be $T_{\mathrm{g}}=$ $561^{\circ} \mathrm{C}, T_{x}=755^{\circ} \mathrm{C}$, and $T_{\mathrm{p}}=779^{\circ} \mathrm{C}$, respectively. The precursor glass was subjected to isothermal heat-treatment at $T_{\mathrm{p}}-50^{\circ} \mathrm{C}$ $\left(729^{\circ} \mathrm{C}\right)$ for different time periods in air to crystallize the $\mathrm{ZrO}_{2}$ phase in the glass. Although it may be better to crystallize the precursor glass at $T_{\mathrm{p}}$ in order to examine the resulting GCs, the GCs obtained at $T_{\mathrm{p}}$ showed a considerable deformation, which is not suitable for evaluation. Therefore, we attempted to prepare the GCs below the $T_{\mathrm{p}}$. As a result, the condition at $T_{\mathrm{p}}-50^{\circ} \mathrm{C}$ provided a less deformed sample so that the $T_{\mathrm{p}}-50^{\circ} \mathrm{C}$ was chosen as the treatment temperature.

\subsection{Characterizations of glass-ceramics}

The GC samples were characterized by XRD analysis, scanning electron microscopy (SEM), transmission electron microscopy (TEM) with energy-dispersive X-ray spectroscopy (EDX). In terms of optical measurements, The PL and PL excitation (PLE) spectra were studied using a spectrofluorometer with a xenon lamp as an excitation source. Internal quantum-yield (QY) of the $\mathrm{PL}$ in the $\mathrm{ZrO}_{2}$ samples was estimated by a PL spectrometer with an integrating sphere (Hamamatsu Photonics: Absolute PL Quantum Yield Measurement System C9920-20). All of the measurements were performed at room temperature.

\section{Results}

\subsection{Phase formation in glass-ceramics}

In Fig. 1, we show the XRD patterns in precursor glasses (bulk state) subjected to heat-treatment for different time periods. In the glasses treated for short times $(1$ and $4 \mathrm{~h}$ ), diffraction peaks appeared mainly at $2 \theta \sim 30^{\circ}$ and $\sim 50^{\circ}$, and the series of peaks were determined to be tetragonal $\mathrm{ZrO}_{2}$ by comparison of ICDD with the diffraction pattern. In the glass treated for $9 \mathrm{~h}$, the additional peaks, e.g., at $2 \theta \sim 28^{\circ}$ and $\sim 31^{\circ}$, appeared and were attributed to formation of monoclinic $\mathrm{ZrO}_{2}$, meaning the coexistence of tetragonal and monoclinic phases. Further increase in the treatment time provided the formation of major monoclinic phase with a minor tetragonal phase $(24 \mathrm{~h})$, and the crystallized phase was eventually converted to a monoclinic ( $48 \mathrm{~h})$. The XRD analysis predicts that precipitation of $\mathrm{ZrO}_{2}$ crystals is almost completed at $1 \mathrm{~h}$, and is subsequently converted gradually into the monoclinic phase by prolongation of treating time. Thus, the precursor glasses crystallized $\mathrm{ZrO}_{2}$ crystals only by means of proper heat-treatment, indicating that $\mathrm{ZrO}_{2}$-crystallized GCs were successfully fabricated.

\subsection{Texture and morphology observation}

In Fig. 2, we show the crystallized textures in GC samples in this study. The SEM and TEM observations revealed that micrometer-sized dendrites with a crystal width of ca. $50 \mathrm{~nm}$ were

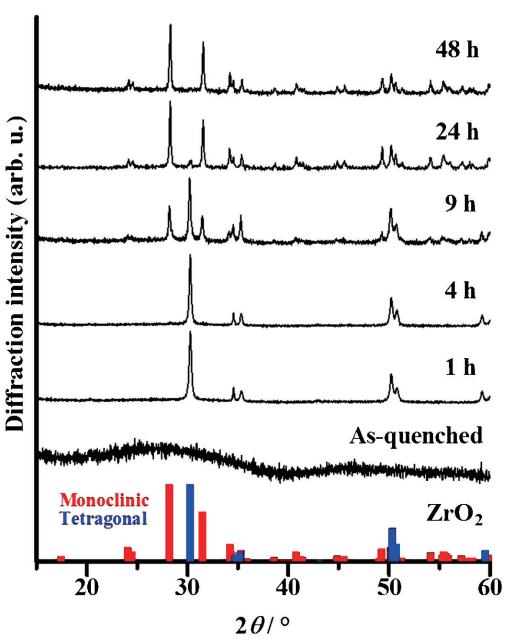

Fig. 1. XRD patterns in as-quenched precursor glass and glasses heattreated at $T_{\mathrm{p}}-50^{\circ} \mathrm{C}\left(729^{\circ} \mathrm{C}\right)$ for $1-48 \mathrm{~h}$. The samples were measured in bulk form. ICDD of monoclinic (\#36-0420; red bars) and tetragonal $\mathrm{ZrO}_{2}$ (\#50-1089; blue bars) are also included.
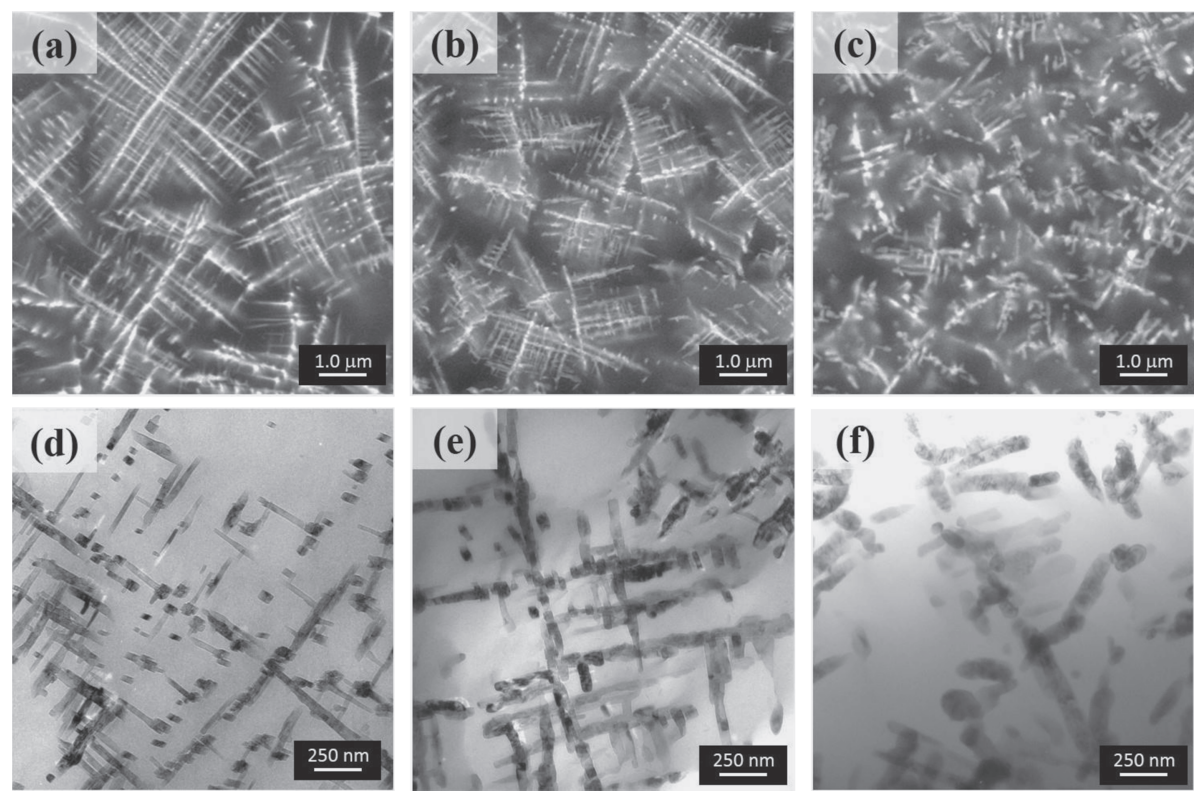

Fig. 2. SEM images for $\mathrm{ZrO}_{2}$-crystallized glass-ceramics obtained by heat-treatment for 1,4 , and $24 \mathrm{~h}$ (a-c) and the corresponding TEM images (1, 4, and $24 \mathrm{~h}$; d-f). 
homogeneously distributed in the sample for $1 \mathrm{~h}$ [Figs. 2(a) and 2(d)]. Elongation of the treatment time provided no significant increase in the number of dendrites, implying that crystallization of $\mathrm{ZrO}_{2}$ dendrites was already finished in the early stage of heattreatment. Interestingly, the elongation also gave the dendrites to be small; $\sim 3.5 \mu \mathrm{m}$ for $1 \mathrm{~h}$ and $\sim 2.0 \mu \mathrm{m}$ for $4 \mathrm{~h}$ [Figs. 2 (b) and 2(e)]. Eventually needle-/rod-like crystals on a few hundred nanometer-scale were formed with a treatment time of $24 \mathrm{~h}$ [Figs. 2(c) and 2(f)]. Basically, the size of crystallized phase in glass tends to increase with the heat-treatment duration. However, the result obtained in this study was the opposite.

To investigate the crystallized texture in detail, we performed an electron diffraction (ED) analysis. In Fig. 3, we show the TEM images and corresponding selected area electron diffraction (SAED) patterns in GC samples for 1, 4, and $24 \mathrm{~h}$. In all the samples, the dendrites indicated a spot-like ED pattern, suggesting that the $\mathrm{ZrO}_{2}$ phases are single domain. In the $\mathrm{GC}$ sample for $1 \mathrm{~h}$, the SAED pattern was assigned to the tetragonal phase with a trace of monoclinic phases [Fig. 3(a)]. The SAED patterns in the $\mathrm{GC}$ samples for 4 and $24 \mathrm{~h}$ were assigned to the monoclinic phase [Figs. 3(b) and 3(c)]. Although the XRD result (Fig. 1) indicates total formation of the tetragonal phase in the GC samples for 1 and $4 \mathrm{~h}$, the SAED patterns in their samples strongly suggest that a nano-sized/small-amount of monoclinic phase, which is hardly observable by means of XRD, is developed. Thus, the series of SAED patterns probably show the transition state from tetragonal to the monoclinic phase.

The EDX analysis was also carried out to determine the element-distribution after the dendrite-formation. In Fig. 4, we show the results of element mapping by means of TEM-EDX analysis in a GC sample for $1 \mathrm{~h}$. One can see that the $\mathrm{Zr}$ element is condensed in the dark regions, corresponding to the dendrites, and is hardly observed in the surrounding region. The other elements are evenly distributed. This strongly suggests that the $\mathrm{ZrO}_{2}$ is almost consumed to form the dendrites during heattreatment for $1 \mathrm{~h}$. The results of EDX analysis also supports the prediction based on the XRD analysis.
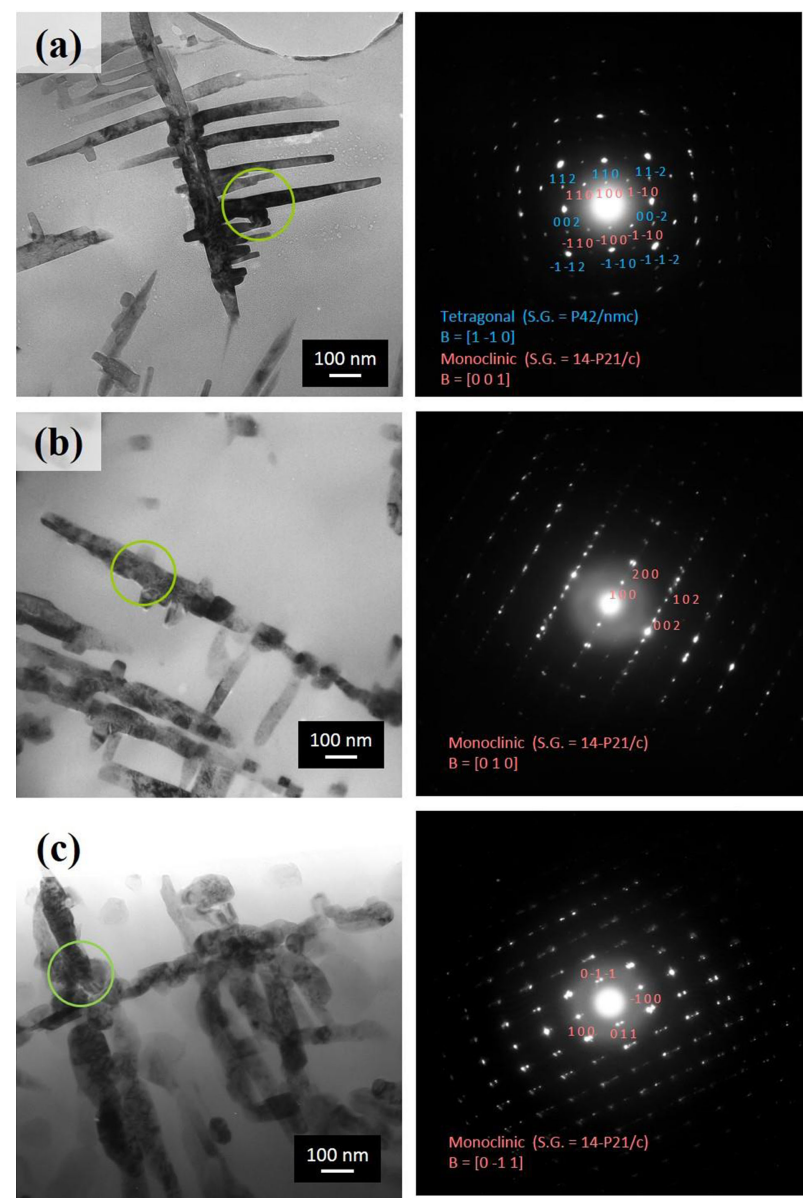

Fig. 3. TEM images (left) and SAED patterns (right) in glass-ceramics obtained by heat-treatment for 1,4 , and $24 \mathrm{~h}(\mathrm{a}-\mathrm{c})$. The green circles correspond to the observed area.

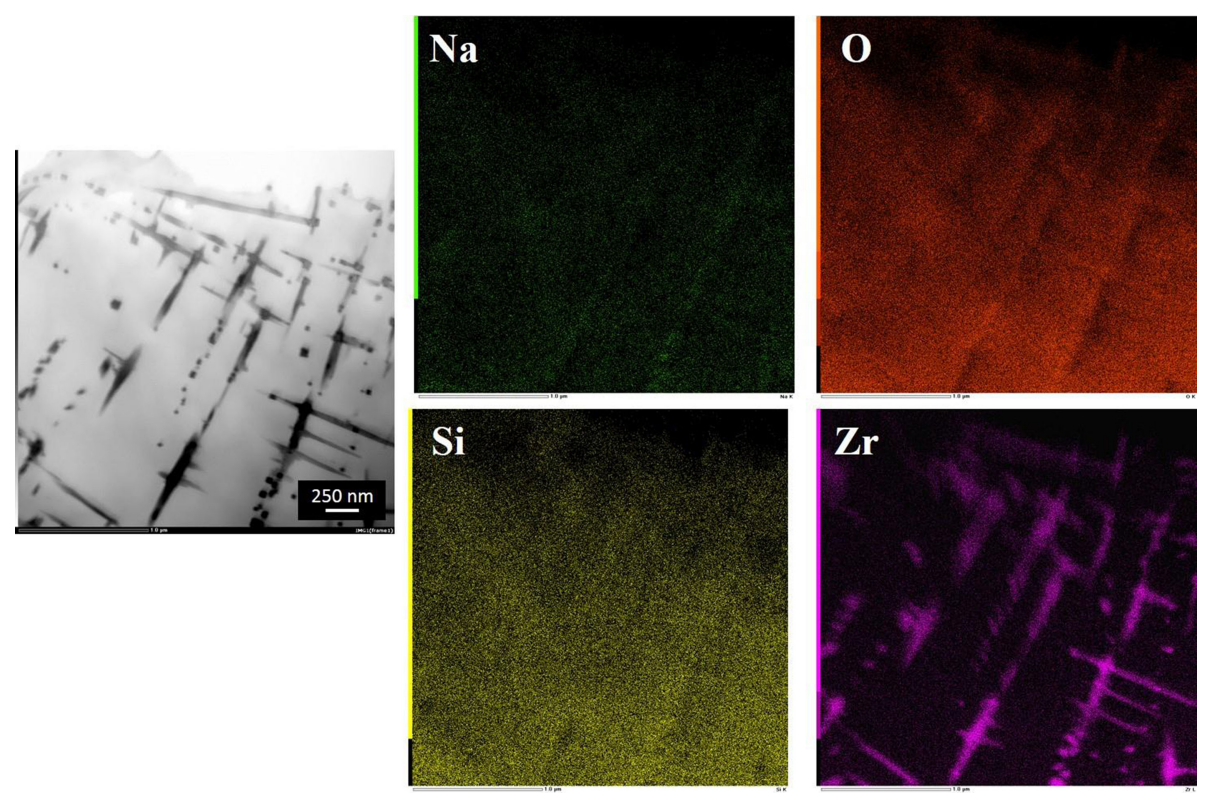

Fig. 4. EDX mapping results for glass-ceramics obtained by heat-treatment for $1 \mathrm{~h}$. 


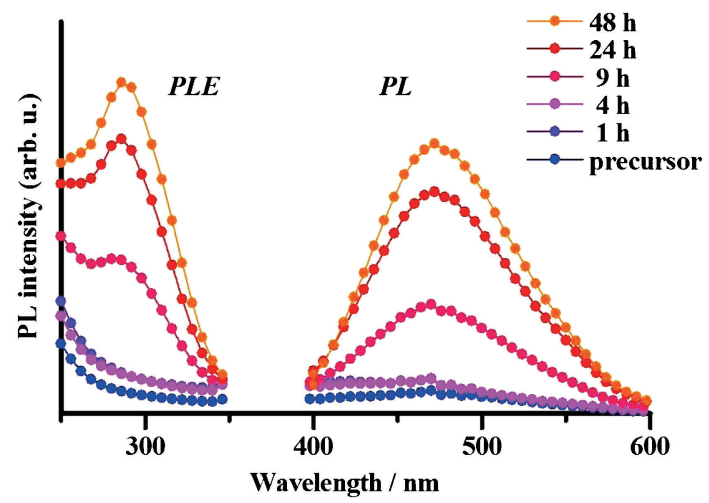

Fig. 5. PL and PLE spectra for the precursor glass and glass-ceramics obtained by the heat-treatment for $1-48 \mathrm{~h}$. Note that the plots of sample for $1 \mathrm{~h}$ is almost superimposed on that of sample for $4 \mathrm{~h}$.

\subsection{Spectroscopic study of glass-ceramics with $\mathrm{ZrO}_{2}$ dendrites}

In Fig. 5, we show the results of spectroscopic measurements of the $\mathrm{ZrO}_{2}$-crystallized GC samples. PL and PLE bands were hardly detected in the samples obtained for 1 and $4 \mathrm{~h}$, which crystallize only the tetragonal phase, as well as the precursor glass. On the other hand, the samples for 9-24h, which consist of monoclinic phase, obvious spectral structures, i.e., a broad PL band at $\sim 480 \mathrm{~nm}$ in the blue region and PLE band at $\sim 280 \mathrm{~nm}$, could be observed. The PL intensity was increased with the treatment time, which is responsible for conversion of the tetragonal phase to the monoclinic phase. The internal QY concerning the blue PL was evaluated to be about $6 \%$ in the GC samples obtained for $48 \mathrm{~h}$, consisting of solely monoclinic $\mathrm{ZrO}_{2}$.

The PL properties of monoclinic $\mathrm{ZrO}_{2}$ are affected by the presence of impurities, and the addition of $\mathrm{TiO}_{2}$, in particular, improves the PL intensity. ${ }^{12)}$ Therefore, we also examined the PL properties of GCs made from the Ti-bearing precursors, i.e., $15 \mathrm{Na}_{2} \mathrm{O}-(15-x) \mathrm{ZrO}_{2}-x \mathrm{TiO}_{2}-30 \mathrm{~B}_{2} \mathrm{O}_{3}-40 \mathrm{SiO}_{2}$ glass. The glasses were heat-treated at $T_{\mathrm{p}}-50 \mathrm{~K}$ for $48 \mathrm{~h}$, and crystallized only the monoclinic phase, as confirmed by XRD analysis. In Fig. 6, we show the optical features of Ti-bearing GC samples. When the pieces of GCs were exposed to UV light at $254 \mathrm{~nm}$, we could visually confirm the brighter blue emission of Ti-bearing GCs than that of base GCs $(x=0)$ [Fig. 5(a)]. In addition, the Tibearing GCs possesses the PL and PLE bands at $\sim 480$ and $\sim 280$ $\mathrm{nm}$, respectively. The spectra of a sample with $x=0.01$ is shown as a representative in the inset. The spectral feature of Ti-bearing GC samples were identical to those of base GCa. On the other hand, the internal QY increased compared to the base GCs and the values were maximized at $x=0.01$, i.e., about $10 \%$ [Fig. 6(b)].

\section{Discussion}

\subsection{Phase and morphological variations of $\mathrm{ZrO}_{2}$ dendrites}

$\mathrm{ZrO}_{2}$ crystals possess polymorphism and related phasetransitions: Monoclinic-tetragonal $\left(\sim 1100-1200^{\circ} \mathrm{C}\right)$ and tetragonal-cubic phase-transitions $\left(>2300^{\circ} \mathrm{C}\right)$. If the tetragonal phase is stabilized below the transition temperature, $\mathrm{Y}_{2} \mathrm{O}_{3}$ is introduced into the $\mathrm{ZrO}_{2}$ phase, the so-called yttria-stabilized zirconia. However, in this study the tetragonal phase was initially crystallized at a temperature much lower than the temperature at which monoclinic-tetragonal phase-transition occurs. Because it is thermodynamically a non-equilibrium, the glass/supercooled- (a)

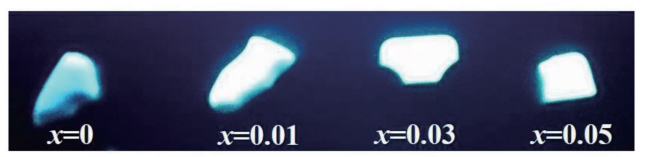

(b)

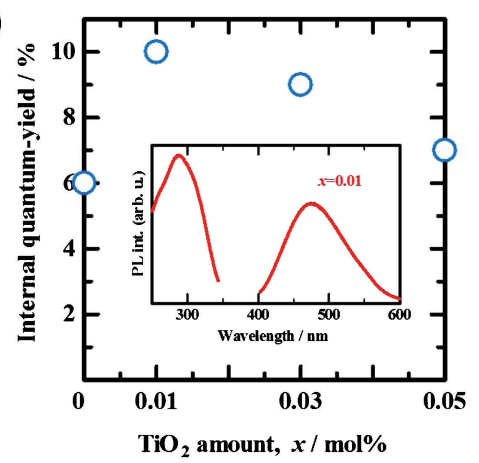

Fig. 6. (a) Photo of glass-ceramics obtained by crystallization of base $(x=0)$ and Ti-bearing precursors. UV-light with a $254 \mathrm{~nm}$-wavelength was irradiated; (b) the spectra of Ti-bearing glass-ceramics with $x=0.01$ (inset) and the values for the internal quantum yield (QY) as a function of $\mathrm{TiO}_{2}$-content, $x$.

liquid (SCL) phase is in a higher energy state than the corresponding crystal phase. If potential curve of a metastable state exists between the SCL and stable-phase potential curves, the metastable phase is able to crystallize prior to the stable phase. ${ }^{22)}$ Indeed, crystallization of the metastable phase is empirically confirmed in several glasses. ${ }^{23), 24)}$ It is considered that tetragonal $\mathrm{ZrO}_{2}$ is freeenergetically higher than monoclinic $\mathrm{ZrO}_{2}$ below the transition temperature. Consequently, the initial crystallization of the tetragonal (high-temperature type) phase and its subsequent formation of the monoclinic (low-temperature type) phase could be interpreted in the same manner.

The formation of $\mathrm{ZrO}_{2}$ dendrites is possibly due to crystalgrowth based on diffusion-controll in GCs, and such dendritic growth is often confirmed by crystallization of glass/SCL in multicomponent systems. ${ }^{25}$ ) The $\mathrm{Zr}$ element, a component of precursor glass, could migrate/diffuse in viscoelastic SCL during heat-treatment (above $T_{\mathrm{g}}$ ), and then be captured competitively in the nearest growth-front of $\mathrm{ZrO}_{2}$ crystals, providing a dendritic structure. In addition, the transformation of $\mathrm{ZrO}_{2}$-dendrites into needle-/rod-like crystals occurred with the elongation of heattreatment (Fig. 2). Taking the XRD results into account, it is suggested that the morphology of the crystallized $\mathrm{ZrO}_{2}$ is changed simultaneously during the transformation. Monoclinic $\mathrm{ZrO}_{2}$ is martensitically transformed into the tetragonal phase, resulting in a large volume change of $\sim 3 \%$ (shrinkage), ${ }^{26)}$ and $\mathrm{ZrO}_{2}$ ceramics therefore involve a strain energy, which is able to induce the ceramic body to destruction. Therefore, the needle-/ rod-like crystals in the sample for $24 \mathrm{~h}$ (Figs. 2 and 3) are supposed to be produced by the destruction of dendrites due to internal strain caused by the volume change based on the phasetransition.

\subsection{Photoluminescent properties of glass- ceramics}

Until now, $\mathrm{ZrO}_{2}$ micro-/nano-powder has been prepared in order to study the physical properties, and tetragonal $\mathrm{ZrO}_{2}$ has been synthesized especially via the sol-gel and aqueous-solution routes. ${ }^{27), 28)}$ This study demonstrates that emissive $\mathrm{ZrO}_{2}$ crystals 
can also be synthesized using the GC technique, and selective crystallization between monoclinic-tetragonal phases can be achieved by changing the heat-treatment time. Spectroscopic study revealed that increases in the heat-treatment time promote the development of a blue PL band and phase-transformation into monoclinic phase in the GCs with $\mathrm{ZrO}_{2}$-dendrites, suggesting that the tetragonal phase is non-emissive.

The maximum internal QY was obtained at $x=0.01$ in the Tibearing GCs [Fig. 5(b)], and the concentration of Ti in $\sim 0.07$ mol\% against the $\mathrm{ZrO}_{2}$ content. Meanwhile, the brightness of blue PL in $\mathrm{Ti}: \mathrm{ZrO}_{2}$ powder reaches a maximum when the Ticoncentration is $0.08 \mathrm{~mol} \% .^{12)}$ The closeness of these values implies that the $\mathrm{TiO}_{2}$ added to the precursor glass is fully incorporated into the crystallized $\mathrm{ZrO}_{2}$ dendrites. In addition, the decrease in QY values above $x=0.01$ is probably explained by so-called concentration quenching, and such decreases are also confirmed in other Ti-bearing phosphors. ${ }^{29)}$ According to Cong et al., the improvement of $\mathrm{PL}$ property in $\mathrm{ZrO}_{2}$ by $\mathrm{TiO}_{2}$-addition is attributed to formation of oxygen-defects caused by $\mathrm{Ti}^{3+}$, which occupies the $\mathrm{Zr}^{4+}$ site, for charge-compensation. ${ }^{16)}$ Assuming this mechanism, we can strongly expect that the formation of $\mathrm{Ti}^{3+}$ into a $\mathrm{ZrO}_{2}$-crystallizing precursor provides an improvement in the $\mathrm{PL}$ performance in the $\mathrm{ZrO}_{2}$-dendrites. Indeed, it is possible to form $\mathrm{Ti}^{3+}$ and introduce it to the crystallizing phase by introducing a reducing agent into the precursor glass: Yoshida et al. have succeeded in fabrication of GCs consisting of $\mathrm{Ti}^{3+}$-doped anatasetype $\mathrm{TiO}_{2}$, and demonstrated the enhancement of photocatalytic properties based on the $\mathrm{Ti}^{3+}$-doping effect. ${ }^{30}$ )

\section{Summary}

For the purpose of fabricating GCs consisting of RE-free phosphor, $\mathrm{ZrO}_{2}$, we prepared $\mathrm{ZrO}_{2}$-containing borosilicate glass, in which $\mathrm{ZrO}_{2}$ is singly crystallizable, and examined the crystallization behavior. The precursor glass precipitated tetragonal $\mathrm{ZrO}_{2}$ with a dendritic structure as the initial phase, and the tetragonal phase was gradually transformed into a monoclinic phase as the heat-treatment time increased. The phase-transformation caused segmentation of the dendrites, resulting in needle-/rodlike $\mathrm{ZrO}_{2}$ crystals on a few hundred nanometer-scale, and also providing an increase in blue PL intensity and its internal QY. Furthermore, the introduction of $\mathrm{TiO}_{2}$ into precursor glass provided further improvement of the PL properties.

Acknowledgements This work was supported from the Ministry of Education, Culture, Sports, Science and Technology (MEXT) of the Japanese Government. The authors would like to thank Dr. Kenichiro Iwasaki, an assistant professor at Tokyo University of Science, for his significant contribution to this study.

\section{References}

1) A. Sakamoto and S. Yamamoto, Int. J. Appl. Glass Sci., 1, 237-247 (2010).

2) T. Honma, N. Ito, T. Togashi, A. Sato and T. Komatsu, J. Power Sources, 227, 31-34 (2013).

3) K. Yoshida, Y. Takahashi, R. Ihara, N. Terakado, T. Fujiwara,
H. Kato and M. Kakihana, APL Mater., 2, 106103 (2014).

4) K. Yamaoka, Y. Takahashi, Y. Yamazaki, N. Terakado, T. Miyazaki and T. Fujiwara, Sci. Rep., 5, 12176 (2015).

5) S. Fujita, A. Sakamoto and S. Tanabe, IEEE J. Sel. Top. Quantum Electron., 14, 1387-1391 (2008).

6) L. Xiao, Q. Xiao, Y. Liu, P. Ai, Y. Li and H. Wang, J. Alloys Compd., 495, 72-75 (2010).

7) D. Chen, S. Liu, Z. Wan and Z. Ji, J. Phy. Chem. C, 120, 21858-21865 (2016).

8) Q. L. M. de Chermont, C. Chanéac, J. Sequin, F. Pellé, S. Maîirejean, J. P. Jolivet, D. Gourier, M. Bessodes and D. Scherman, Proc. Natl. Acad. Sci. U.S.A., 104, 9266-9271 (2007).

9) Y. Yamaoka and T. Takamatsu, J. Kyoto Pref. Univ. Med., 122, 219-229 (2013) [In Japanese].

10) K. Okabe, N. Inada, C. Gota, Y. Harada, T. Funatsu and S. Uchiyama, Nat. Cummun., 3, 705 (2011).

11) N. Onoue, Sendai Med. Center J., 2, 25-36 (2012) [In Japanese].

12) J. F. Sarver, J. Electrochem. Soc., 113, 124-128 (1966).

13) C. Bettinali, G. Ferraresso and J. W. Manconi, J. Chem. Phys., 50, 3957-3961 (1969).

14) A. Emeline, G. V. Kataeva, A. S. Litke, A. V. Rudakova, V. K. Ryabchuk and N. Serpone, Langmuir, 14, 5011-5022 (1998).

15) T. Shimizu, K. Uheda, H. Takizawa, T. Endo and M. Shimada, J. Jpn. Soc. Pow. Pow. Metal., 46, 175-179 (1999) [In Japanese]

16) Y. Cong, B. Li, B. Lei and W. Li, J. Lumin., 126, 822-826 (2007).

17) Y. Cong, B. Li, X. J. Wang, B. Lei and W. Li, J. Electrochem. Soc., 155, K195-K198 (2008).

18) K. Smits, L. Grigorjeva, D. Millers, A. Sarakovskie, J. Grabis and W. Lojkowski, J. Lumin., 131, 2058-2062 (2011).

19) Z. Wang, J. Zhang, G. Zheng, Y. Liu and Y. Zhao, J. Lumin., 132, 2817-2821 (2012).

20) V. Kiisk, L. Puust, K. Utt, A. Maaroos, H. Mändar, E. Viviani, F. Piccinelli, R. Saar, U. Joost and I. Sildos, J. Lumin., 174, 49-55 (2016).

21) R. D. Maschio and P. Scardi, Ceram. Int., 17, 31-36 (1991).

22) T. Komatsu, J. Non-Cryst. Solids, 428, 156-175 (2015).

23) H. G. Kim, T. Komatsu, K. Shioya, K. Matusita, K. Tanaka and K. Hirao, J. Non-Cryst. Solids, 208, 303-307 (1996).

24) V. N. Sigaev, S. V. Lotarev, E. N. Smelyanskaya, P. D. Sarkisov, A. A. Volkov, G. A. Komandin, V. V. Koltashev and V. G. Plotnichenko, Glass Phys. Chem., 32, 497-504 (2006).

25) Y. Takahashi, M. Kinoshita, T. Miyazaki, M. Osada, N. Terakado and T. Fujiwara, Appl. Phys. Lett., 107, 061902 (2015).

26) R. N. Patil and E. C. Subbarao, Acta Crystallogr., Sect. A: Cryst. Phys., Diffr., Theor. Gen. Crystallogr., 26, 535-542 (1970).

27) K. Sato, H. Abe and S. Ohara, J. Am. Chem. Soc., 132, 25382539 (2010).

28) S. Kumar and A. K. Ojha, Mater. Chem. Phys., 169, 13-20 (2016).

29) K. Iwasaki, Y. Takahashi, H. Masai and T. Fujiwara, Opt. Express, 17, 18054-18062 (2009).

30) K. Yoshida, H. Takahashi, H. Masai, N. Terakado, Y. Takahashi, T. Fujiwara, H. Kato and M. Kakihana, Int. J. Hydrogen Energy, 41, 22055-22058 (2016). 